\title{
Relação entre faixas de renda e o perfil dos consumidores de carne bovina da região sul do Brasil
}

\author{
Relationship between level income and profile of beef consumers in southern Brazil \\ Jackeline Karsten Kirinus', Ana Paula Burin Fruet ${ }^{2}$, Ana Carolina Kohlarausch Klinger ${ }^{3}$, \\ Andréa Cristina Dörr ${ }^{4}$, José Laerte Nörnberg ${ }^{5}$ \\ 1,2,3,5 Departamento de Ciência e Tecnologia dos Alimentos, Área Quaildade dos alimentos - Universidade Federal de Santa Maria \\ ${ }^{4}$ Departamento de Ciências Econômicas, Área: Agronegócio- Universidade Federal de Santa Maria
}

\section{Resumo}

A carne bovina está presente na alimentação dos brasileiros e sua demanda está ligada a diversos fatores como: preço, qualidade, preferência, sabor e, principalmente, padrões socioeconômicos dos consumidores. O objetivo deste trabalho foi relacionar a renda assim como, caracterizar outros fatores que determinam e influenciam o consumo de carne bovina na população de Santa Maria, RS, Brasil. Foram aplicados 797 questionários semi-estruturados por 16 entrevistadores devidamente treinados. Após aplicação dos questionários, os dados foram tabulados e analisados. Dentre os entrevistados, $98,37 \%$ consomem carne bovina. A costela é o principal corte de preferência, no entanto, os consumidores compram efetivamente o coxão mole. O maior percentual de entrevistados auferem de 1 a 3 salários mínimos mensais. A escolha pelo local de compra do produto cárneo é atribuída preferencialmente a proximidade da residência dos entrevistados. Os consumidores estariam dispostos a pagar mais por uma carne certificada pela maciez. Existe uma tendência a aumentar o consumo e valor pago por quilograma de carne bovina na medida em que aumenta o poder aquisitivo do consumidor. Desta forma, é possível inferir que o poder aquisitivo da população interfere na compra dos diferentes cortes bovinos consumidos.

Palavras Chave: condições socioeconômicas, cortes bovinos, poder aquisitivo, preferência do consumidor.

\begin{abstract}
The beef is present in the diet of Brazilians and their demand is linked to several factors such as price, quality, preference, flavor, and mainly socioeconomics standards of consumers. The aim of this research was to relate the income as well as characterize other factors that determine and influence the consumption of beef in the population of Santa Maria, RS, Brazil. We applied 797 semi-structured questionnaires by 16 trained interviewers. After the application of the questionnaires, the data were tabulated and analyzed. Among the respondents, $98.37 \%$ consume beef. The rib is the main cut chosen by consumers, however, consumers buy effectively topside. The highest percentage of respondents earn of 1-3 minimum wage monthly. The choice of the place that consumers purchase meat products is preferably given by their proximity of residence. Consumers would be willing to pay more for a beef certified by its tenderness. There is a tendency to increase consumption and price paid per kilogram of beef with the increase of the consumers purchasing power. Thus, it is possible to conclude that the purchasing power of the population interferes with the purchase of different cuts of beef consumed.
\end{abstract}

Keywords: socioeconomic conditions, meat cuts, purchasing power, consumer preference 


\section{INTRODUÇÃO}

O Brasil possui uma população de aproximadamente 195,2 milhões de habitantes e apesar das mudanças que estão ocorrendo no país, a distribuição de renda permanece desigual. Observa-se que $30,5 \%$ da população declaram não possuir renda; em contrapartida, $0,5 \%$ dos habitantes possuem renda maior que 20 salários mínimos mensais. Neste contexto, a renda per capita dos brasileiros aumentou nas últimas décadas, passando de R \$ 591,00 em 2001 para $R \$ 783,00$ em 2011 (IBGE, 2012).

Ao longo das últimas décadas diversas mudanças socioeconômicas e demográficas vêm ocorrendo em todas as regiões do mundo (SCHLINDWEIN; KASSOUF, 2006). Assim, pode-se evidenciar um avanço no desenvolvimento econômico e humano. Grande parte dos brasileiros são beneficiados através das mudanças relacionadas com as melhorias no padrão de vida material, as condições de saúde, o maior tempo de vida, a ampliação no exercício da cidadania, e as maiores oportunidades de aperfeiçoamento pessoal (CACCIAMALI, 2002).

A carne bovina está presente na alimentação dos brasileiros e sua demanda está ligada a diversos fatores como: preço, qualidade, preferência, sabor e, principalmente, a renda (MAZZUCHETTI; BATALHA, 2004). Assim, pode-se dizer que quando há aumento da renda existe tendência em elevar o consumo de carne bovina de primeira (cortes nobres), já a mesma relação não ocorre com carne bovina de segunda e carne de frango (DE CARVALHO; BACCHI, 2007; BENÍTEZ et al., 2010). Desta forma, as tendências no consumo de carne bovina estão aliadas as características socioeconômicas do consumidor, o que constitui parâmetros importantes a fim de identificar os fatores que influenciam na compra do produto (SILVA, 2009).

Com intuito de compreender as relações entre o consumo de cortes cárneos e renda da população, este artigo busca relacionar a renda assim como, caracterizar outros fatores que determinam e influenciam o consumo de carne bovina na população de Santa Maria, RS, Brasil.

\section{METODOLOGIA}

A pesquisa foi realizada no município de Santa Maria, Rio Grande do Sul, Brasil no período de março a abril de 2011 (Latitude: $29^{\circ} 41^{\prime} 03$ "S e Longitude: $53^{\circ} 48$ '25 "W). Foram aplica- dos 797 questionários semi-estruturados por 16 entrevistadores devidamente treinados, os quais explicaram algumas características do mesmo aos consumidores, esclarecendo qualquer dúvida antes do entrevistado responder as perguntas, segundo aprovação do comitê de ética CAAE número 06049312.3.0000.5346. O questionário mesclou questões fechadas e abertas com o intuito de obter dados qualitativos e quantitativos (GIL, 1999; NEUMAN, 2009).

Os entrevistados foram selecionados de forma aleatória em frente a supermercados distribuídos nas oito zonas administrativas do município, estudantes universitários, idosos e transeuntes do calçadão Salvador Isaías (via pública de grande fluxo). O processo de seleção da amostra aleatória atribui a cada indivíduo da população a mesma probabilidade de ser incluído na amostra (NEUMAN, 2009).

Após aplicação dos questionários, os dados foram tabulados e analisados, através do Pacote Estatístico para as Ciências Sociais - Statistical Package for the Social Sciences (SPSS) versão 15.0 com auxílio do teste Chi-quadrado. Os valores foram considerados estatisticamente significativos quando $\mathrm{p}<0,05$.

\section{RESULTADOS E DISCUSSÃO}

Como ferramenta operativa, a aplicação de questionários em pesquisas de investigação sistemática é amplamente utilizada para caracterizar a opinião de uma dada população sobre um assunto específico. Desta forma, este processo auxilia o pesquisador no acesso a eventos já ocorridos, elaboração de perfis de consumo e comportamento, além das aplicações de diversos diagnósticos. É importante analisar as limitações que esse tipo de pesquisa está sujeita, decorrente do tamanho da amostra utilizada, da falta de método estatístico de amostragem mais apropriada, da variabilidade das interpretações na realização da pesquisa e seleção dos questionamentos (VELHO, 2009). Neste sentido, esta ferramenta limita as generalizações, contudo não invalida a pesquisa como sinalizadora de tendências.

A partir do número total de entrevistados, $98,37 \%$ (784/797) afirmam que consomem carne bovina, enquanto somente $1,64 \%(13 / 797)$ falaram que não consomem. Portanto, pode-se verificar que a carne bovina representa uma grande importância como fonte de proteína, além disso, segundo Monteiro e Caswell (2004) ela está presente entre os principais itens que compõem a cesta de consumo 
da população brasileira.

Este resultado vai ao encontro das perpectivas da FAO (2013), ou seja, que ocorrerá um aumento da demanda de carne bovina, principalmente devido ao aumento da produção $(9,5$ milhões de toneladas) e a melhoria das condições de vida, o que proporcionará um incremento na cesta alimentar da população brasileira. Pode-se dizer que o consumo de proteína animal no âmbito doméstico vem aumentando. CANFAX (2012) constatou que consumo per capita de carne bovina aumentou $5,2 \%$ desde 2006, ou seja, passou de 36 $\mathrm{kg}$ para quase $38 \mathrm{~kg}$, em 2012.

Conforme dados apresentados na Tabela 1 observa-se que a grande maioria dos entrevistados possui uma renda familiar ou pessoal de 1 a 3 salários mínimos e média de 10,58 anos de estudo. No entanto, a média de idade e anos de estudos dos entrevistados é respectivamente de 41,15 e 11,57. A grande variação do desvio padrão pode ser atribuída a heterogeneidade das diferentes populações de análise.

Kotler (1998) aponta que a variável cultural é de grande influência no consumo de bens alimentícios. Neste contexto, Schlindwein e Kassouf (2006) relatam que o nível de renda, urbanização e composição familiar foram altamente significativas para determinar o consumo de carne. Além disso, o aumento na renda e nível de escolaridade eleva a probabilidade de consumo e despesa domiciliar com a carne bovina. Em contrapartida, Coelho et al. (2009) afirmam que o nível educacional parece estar negativamente correlacionado com a probabilidade de aquisição dos produtos básicos da cesta domiciliar.

Desta forma, saber quais os cortes bovinos que os consumidores mais gostam e mais compram, assim como os atributos que influenciam o momento da compra são extremamente relevantes para a definição da situação comercial e cultural da carne bovina na esfera de estudo.

Para melhor compreensão, na Tabela 2 foram analisados os cinco primeiros cortes bovinos de preferência dos consumidores. Verificou-se que 156/697 (22,38\%) dos entrevistados escolherem a costela como corte que mais gostam $(p<0,05)$. Sugere-se que o resultado encontrado está fortemente ligado com a cultura e tradição do estado do Rio Grande do Sul, devido ao churrasco ser o prato principal da culinária gaúcha.

Em estudo realizado por Farias et al. (2010), dentre os cortes que possuem a maior preferência no município de Bagé, a picanha foi a mais citado $(17 \%)$, seguido pela costela $(14,9 \%)$. Por outro lado, considerando o estado do Rio Grande a costela possui a preferência de $26,2 \%$, e a picanha de $11,9 \%$.

Em contrapartida De Vasconcellos et al. (2012) relatam que a costela é o corte de predileção do Pampa com 19,6\%, além de ser a mais consumida com 21,6\%. Também, Pinheiro et al. (2010) observaram que o tipo de corte mais consumido é a costela representando $53 \%$ da preferência dos consumidores seguido do coxão mole (24\%).

Quando relatados os atributos elegidos

Tabela 1 - Caracterização dos entrevistados por renda pessoal ou familiar em salários mínimos, idade e estudo em anos

\begin{tabular}{|c|c|c|c|c|c|c|}
\hline \multirow{3}{*}{$\begin{array}{l}\text { RENDA EM } \\
\text { FAIXAS }\end{array}$} & \multicolumn{3}{|c|}{ IDADE EM ANOS } & \multicolumn{3}{|c|}{ ANOS DE ESTUDO } \\
\hline & \multicolumn{2}{|c|}{ Entrevistados } & \multirow{2}{*}{$\begin{array}{l}\text { Idade } \\
\text { Desvio } \\
\text { Padrão }\end{array}$} & \multicolumn{2}{|c|}{ Entrevistados } & \multirow{2}{*}{$\begin{array}{c}\text { Estudo } \\
\text { Desvio } \\
\text { Padrão }\end{array}$} \\
\hline & $\mathrm{N}^{* *}$ & Média & & $\mathrm{N}^{* *}$ & Média & \\
\hline Menos de $1 \mathrm{SM}^{*}$ & 38 & 32,21 & 18,32 & 37 & 11,98 & 4,18 \\
\hline 1 a 3 & 363 & 41,56 & 18,65 & 360 & 10,58 & 3,75 \\
\hline 3 a 4 & 4 & 32,00 & 23,33 & 4 & 13,00 & 1,63 \\
\hline 4 a 6 & 153 & 42,13 & 18,90 & 150 & 12,52 & 3,89 \\
\hline 7 a 9 & 73 & 41,75 & 16,69 & 71 & 12,64 & 3,02 \\
\hline 10 a 15 & 48 & 45,85 & 16,70 & 46 & 13,06 & 3,44 \\
\hline 16 a 20 & 10 & 27,10 & 15,67 & 10 & 13,60 & 2,87 \\
\hline Mais de $20 \mathrm{SM}^{*}$ & 8 & 35,12 & 21,74 & 8 & 14,75 & 2,86 \\
\hline TOTAL & 697 & 41,15 & 18,56 & 686 & 11,57 & 3,83 \\
\hline
\end{tabular}

"Salário mínimo; ${ }^{* *}$ Tamanho da amostra. 
Tabela 2 - Corte de carne bovina de preferência dos consumidores

\begin{tabular}{|c|c|c|c|c|c|c|c|c|c|c|}
\hline \multirow{3}{*}{$\begin{array}{l}\text { RENDA } \\
\text { EM FAIXAS }\end{array}$} & \multicolumn{10}{|c|}{$\begin{array}{l}\text { CORTE QUE MAIS GOSTA }{ }^{1} \\
\qquad(\mathrm{~N}=697)\end{array}$} \\
\hline & \multicolumn{2}{|c|}{$\begin{array}{l}\text { Corte } 1 \\
\text { Costela } \\
\end{array}$} & \multicolumn{2}{|c|}{$\begin{array}{l}\text { Corte } 2 \\
\text { Picanha }\end{array}$} & \multicolumn{2}{|c|}{$\begin{array}{c}\text { Corte } 3 \\
\text { Filé Mignon }\end{array}$} & \multicolumn{2}{|c|}{$\begin{array}{c}\text { Corte } 4 \\
\text { Coxão mole }\end{array}$} & \multicolumn{2}{|c|}{$\begin{array}{l}\text { Corte } 5 \\
\text { Chuleta } \\
\end{array}$} \\
\hline & $\mathrm{N}^{* *}$ & $\%$ & $\mathrm{~N}^{* *}$ & $\%$ & $\mathrm{~N}^{* *}$ & $\%$ & $\mathrm{~N}^{* *}$ & $\%$ & $\mathrm{~N}^{* *}$ & $\%$ \\
\hline Menos de $1 \mathrm{SM}^{*}$ & 10 & 6,4 & 5 & 4,1 & 8 & 9,1 & 3 & 4,4 & 2 & 3,7 \\
\hline 1 a 3 & 93 & 59,6 & 56 & 45,5 & 30 & 34,1 & 40 & 58,8 & 33 & 61,1 \\
\hline 3 a 4 & 1 & 0,6 & 0 & 0,0 & 0 & 0,0 & 1 & 1,5 & 0 & 0,0 \\
\hline 4 a 6 & 34 & 21,8 & 35 & 28,5 & 21 & 23,9 & 10 & 14,7 & 10 & 18,5 \\
\hline 7 a 9 & 9 & 5,8 & 16 & 13,0 & 12 & 13,6 & 7 & 10,3 & 5 & 9,3 \\
\hline 10 a 15 & 5 & 3,2 & 8 & 6,5 & 11 & 12,5 & 5 & 7,4 & 4 & 7,4 \\
\hline 16 a 20 & 3 & 1,9 & 1 & 0,8 & 2 & 2,3 & 1 & 1,5 & 0 & 0,0 \\
\hline Mais de $20 \mathrm{SM}^{*}$ & 1 & 0,6 & 2 & 1,6 & 4 & 4,5 & 1 & 1,5 & 0 & 0,0 \\
\hline TOTAL & 156 & 100,0 & 123 & 100,0 & 88 & 100,0 & 68 & 100,0 & 54 & 100,0 \\
\hline
\end{tabular}

*Salário mínimo; **Tamanho da amostra; \% = percentual; ${ }^{1}$ Chi-quadrado de Pearson 0,001.

Tabela 3 - Corte de carne bovina mais consumida pelos entrevistados

\begin{tabular}{|c|c|c|c|c|c|c|c|c|c|c|}
\hline \multirow{3}{*}{$\begin{array}{l}\text { RENDA EM } \\
\text { FAIXAS }\end{array}$} & \multicolumn{10}{|c|}{$\begin{array}{l}\text { CORTE QUE MAIS COMPRA }{ }^{1} \\
\qquad(\mathrm{~N}=689)\end{array}$} \\
\hline & \multicolumn{2}{|c|}{$\begin{array}{c}\text { Corte } 1 \\
\text { Coxão mole } \\
\end{array}$} & \multicolumn{2}{|c|}{$\begin{array}{l}\text { Corte } 2 \\
\text { Chuleta } \\
\end{array}$} & \multicolumn{2}{|c|}{$\begin{array}{l}\text { Corte } 3 \\
\text { Costela } \\
\end{array}$} & \multicolumn{2}{|c|}{$\begin{array}{l}\text { Corte } 4 \\
\text { Paleta } \\
\end{array}$} & \multicolumn{2}{|c|}{$\begin{array}{l}\text { Corte } 5 \\
\text { Patinho } \\
\end{array}$} \\
\hline & $\mathrm{N}^{* *}$ & $\%$ & $\mathrm{~N}^{* *}$ & $\%$ & $\mathrm{~N}^{* *}$ & $\%$ & $\mathrm{~N}^{* *}$ & $\%$ & $\mathrm{~N}^{* *}$ & $\%$ \\
\hline Menos de $1 \mathrm{SM}^{*}$ & 8 & 5,1 & 1 & 1,1 & 8 & 11 & 3 & 4,3 & 5 & 8,3 \\
\hline 1 a 3 & 86 & 55,1 & 41 & 44,6 & 50 & 68,5 & 42 & 60 & 28 & 46,7 \\
\hline 3 a 4 & 3 & 1,9 & 0 & 0 & 0 & 0 & 0 & 0 & 0 & 0 \\
\hline 4 a 6 & 34 & 21,8 & 24 & 26,1 & 7 & 9,6 & 18 & 25,7 & 19 & 31,7 \\
\hline 7 a 9 & 12 & 7,7 & 16 & 17,1 & 3 & 4,1 & 4 & 5,7 & 6 & 10,0 \\
\hline 10 a 15 & 8 & 5,1 & 8 & 8,7 & 4 & 5,5 & 3 & 4,3 & 2 & 3,3 \\
\hline 16 a 20 & 3 & 1,9 & 1 & 1,1 & 0 & 0 & 0 & 0 & 0 & 0 \\
\hline Mais de $20 \mathrm{SM}^{*}$ & 2 & 1,3 & 1 & 1,1 & 1 & 1,4 & 0 & 0 & 0 & 0 \\
\hline TOTAL & 156 & 100,0 & 92 & 100,0 & 73 & 100,0 & 70 & 100,0 & 60 & 100,0 \\
\hline
\end{tabular}

*Salário mínimo; **Tamanho da amostra; \% = percentual; ${ }^{1}$ Chi-quadrado de Pearson de 0,031 
na escolha do corte que mais gostam, não foram verificadas diferenças estatísticas significativas ( $p$ $>0,05$ ), apesar de terem sido citados os atributos sabor, maciez e forma de preparo. Segundo Sepúlveda et al. (2011), a avaliação direta da carne é um dos aspectos que mais valorizados pelos consumidores para obter informações sobre a qualidade no momento da compra. Delgado et al. (2012) afirmaram que as preferências sabor e maciez são as mais citadas para a escolha de cortes bovinos.

$\mathrm{Na}$ Tabela 3, foram relatados os cinco primeiros cortes que os entrevistados efetivamente mais compram. Pode-se observar que o coxão de dentro $156 / 689(22,64 \%)$ foi o corte bovino mais citado pelos consumidores $(\mathrm{p}<0,05)$.

Quando relatados os atributos na escolha do corte que efetivamente mais compram, não foi verificada diferença estatística ( $p>0,05)$, apesar de serem citados os atributos sabor, preço e maciez. Neste sentido, evidencia-se que ao questionar atributos de compra, o preço está presente nas variáveis lembradas, portanto fica clara a partição do custo da carne na decisão de compra e ainda pode-se inferir que muitas vezes o corte de predileção não é o produto consumido.

Tal afirmativa é justificada, por exemplo, pelo alto custo do filé mignon e picanha que foi amplamente citada como corte preferencial.
Segundo levantamento realizado por Silveira et al. (2009) a picanha apresentou valor de mercado mais elevado quando comparado com cortes como coxão mole, chuleta, costela e paleta.

Os consumidores buscam cada vez mais alimentos de alta qualidade. Neste sentido fatores como: boa aparência, adoção de procedimentos de rastreabilidade, higiene no momento da compra, qualidade nutricional, maciez e vida útil prolongada são levados em conta pelo consumidor (AYMERICH et al., 2008; BARCELLOS et al., 2012). Portanto, a qualidade deve ir além da fabricação do produto cárneo, faz-se necessário orientar e supervisionar o processo de embalagem, transporte e exposição do produto até este chegar ao consumidor final, promovendo, assim, a segurança alimentar e certificação.

Os entrevistados apontaram o local de compra do corte e justificaram esta escolha. No entanto, apesar de terem sido citados locais como: mercado, hipermercado, açougue, direto do produtor e restaurante, não foi observada diferença significativa com relação ao local de preferência no momento da compra. Por outro lado, o atributo de escolha conferido ao local da compra está principalmente ligado a proximidade da residência dos consumidores em nível de $5 \%$ de significância (Tabela 4).

Tabela 4 - Atributo que influencia o local de compra da carne bovina pelos entrevistados conforme a renda familiar ou pessoal em salários mínimos

\begin{tabular}{|c|c|c|c|c|c|c|}
\hline \multirow{3}{*}{$\begin{array}{l}\text { RENDA EM } \\
\text { FAIXAS }\end{array}$} & \multicolumn{6}{|c|}{$\begin{array}{l}\text { PORQUE COMPRA NESTE LOCAL }{ }^{1} \\
\qquad(\mathrm{~N}=685)\end{array}$} \\
\hline & \multicolumn{2}{|c|}{$\begin{array}{c}\text { Razão } 1 \\
\text { Proximidade } \\
\end{array}$} & \multicolumn{2}{|c|}{$\begin{array}{c}\text { Razão } 2 \\
\text { Confianca } \\
\end{array}$} & \multicolumn{2}{|c|}{$\begin{array}{c}\text { Razão } 3 \\
\text { Preço } \\
\end{array}$} \\
\hline & $\mathrm{N}^{* *}$ & $\%$ & $\mathrm{~N}^{* *}$ & $\%$ & $\mathrm{~N}^{* *}$ & $\%$ \\
\hline Menos de $1 \mathrm{SM}^{*}$ & 21 & 6,5 & 4 & 2,4 & 10 & 9,3 \\
\hline 1 a 3 & 186 & 57,4 & 79 & 46,5 & 65 & 60,7 \\
\hline 3 a 4 & 1 & 0,3 & 1 & 0,6 & 1 & 0,9 \\
\hline 4 a 6 & 68 & 21,8 & 46 & 27,1 & 17 & 15,9 \\
\hline 7 a 9 & 27 & 8,3 & 26 & 15,3 & 7 & 6,5 \\
\hline 10 a 15 & 17 & 5,2 & 9 & 5,3 & 4 & 3,7 \\
\hline 16 a 20 & 3 & 0,9 & 2 & 1,2 & 3 & 2,8 \\
\hline Mais de $20 \mathrm{SM}^{*}$ & 1 & 0,3 & 3 & 1,8 & 0 & 0 \\
\hline TOTAL & 324 & 100,0 & 170 & 100,0 & 107 & 100,0 \\
\hline
\end{tabular}

"Salário mínimo; **Tamanho da amostra; \% = percentual; ${ }^{1}$ Chi-quadrado de Pearson de $0,00$. 
Para Brisola e Castro (2005), a comodidade e a praticidade oferecidas pelos pontos de compra são atributos valorizados pelos consumidores de carne bovina; eles ainda afirmam que a proximidade da residência é uma qualidade bastante valorizada pelos consumidores de faixa de renda intermediária. Por outro lado, Bliska et al. (1998) citam a falta de confiança como uma dos principais entraves à organização da cadeia comercial, enquanto Sepúlveda et al. (2011) afirmam que o preço influencia na aquisição de determinados cortes bovinos.

Demonstra-se na Tabela 5 quais foram os primeiros cortes bovinos que o consumidor estaria disposto a pagar mais pela certificação da maciez. A maioria dos questionados pagaria de $\mathrm{R} \$ 0,10 \mathrm{a}$ $\mathrm{R} \$ 2,00$ a mais, de modo que a picanha e o coxão duro foram os cortes mais escolhidos $(p<0,05)$. Apesar da costela ter sido o corte mais citado na disposição do consumidor em pagar a mais pela certificação da maciez da carne bovina, não foi verificada diferença significativa $(p>0,05)$ para este corte.

Foi identificado que os consumidores estariam dispostos a pagar menos de $20 \%$ pela maciez do corte. Os resultados podem ser explicados pelo fato do elevado preço da carne. Este resultado vai ao encontro do mostrado por Velho et al. (2009), em que consumidores de carne exigem alimentos de qualidade e certificação, porém, estes estão dispostos a pagar somente um pouco a mais pela certificação, em comparação ao valor atual de mercado, provavelmente pelo fato de sua renda mensal não permitir maior valorização desse atributo.

O surgimento de novas formas de organização entre os diversos segmentos da cadeia da carne bovina vêm sendo incentivadas, com a finalidade de garantir a competitividade do setor (FERREIRA, 2002), a partir da diferenciação do produto final originário das cadeias e, consequentemente, maior agregação de valor ao mesmo (PATIÑO et al., 2008).

$\mathrm{Na}$ avaliação do consumo semanal em quilogramas por renda pessoal ou familiar e o valor médio pago em reais por quilograma (Tabela 6), verifica-se que existe uma tendência a aumentar o consumo e valor pago pelo quilo de carne bovina, na medida em que, aumenta o poder aquisitivo do consumidor. Schlindwein e Kassouf (2006), observaram que a renda domiciliar aumenta a probabilidade do consumo e despesa na aquisição de carne, além de afirmar que um aumento de $10 \%$ na renda domiciliar eleva o gasto com carne bovina em 2,8\%.

Ainda Pes et al. (2012) afirmam que a elevação na renda da população gera aumento no consumo de alimentos protéicos. Portanto, a demanda de carne bovina está condicionada à renda, já a oferta de carne tende a diminuir em decorrência da elevação do preço do boi, o que pode ser justificado pela menor quantidade adquirida pelos frigoríficos implicando assim, em queda na quantidade ofertada no mercado.

Também Viana e Silveira (2005), relatam que o perfil da cidade influencia o preço pago por

Tabela 5 - Relação dos primeiros cortes que o consumidor estaria disposto a pagar mais pela certificação da maciez da carne bovina em faixas de reais

\begin{tabular}{|c|c|c|c|c|}
\hline \multirow{3}{*}{ FAIXAS EM REAIS } & \multicolumn{4}{|c|}{ CORTES BOVINOS } \\
\hline & \multicolumn{2}{|c|}{ Picanha $^{\mathrm{a}}$} & \multicolumn{2}{|c|}{ Coxão duro ${ }^{b}$} \\
\hline & $\mathrm{N}^{*}$ & $\%$ & $\mathrm{~N}^{*}$ & $\%$ \\
\hline Menos de $20 \%(\mathrm{R} \$ 0,10$ a 2,00$)$ & 42 & 35,9 & 26 & 44,8 \\
\hline 21 a $30 \%(R \$ 2,10$ a 3,00$)$ & 11 & 9,4 & 16 & 27,6 \\
\hline 31 a $40 \%(\mathrm{R} \$ 3,10$ a 4,00$)$ & 7 & 6,0 & 7 & 12,1 \\
\hline 41 a $50 \%(\mathrm{R} \$ 4,10$ a 5,00$)$ & 25 & 21,4 & 3 & 5,2 \\
\hline Mais de 50 (Mais de $\mathrm{R} \$ 5,00$ ) & 32 & 27,4 & 6 & 10,3 \\
\hline TOTAL & 117 & 100,0 & 58 & 100,0 \\
\hline
\end{tabular}

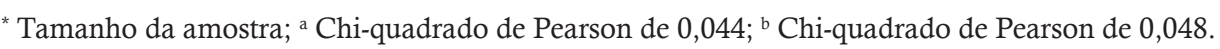


Tabela 6 - Caracterização do consumo semanal e do valor pago em reais por quilograma de carne bovina conforme a renda pessoal ou familiar em salários mínimos dos entrevistados

\begin{tabular}{|c|c|c|c|c|c|c|}
\hline \multirow{3}{*}{$\begin{array}{c}\text { RENDA EM } \\
\text { FAIXA }\end{array}$} & \multicolumn{3}{|c|}{$\begin{array}{c}\text { QUANTIDADE QUE } \\
\text { COMPRAPOR SEMANA }\end{array}$} & \multicolumn{3}{|c|}{$\begin{array}{c}\text { VALOR PAGO POR } \\
\text { KgEMREAIS }\end{array}$} \\
\hline & \multicolumn{3}{|c|}{$\mathrm{kg}$} & \multicolumn{3}{|c|}{$\mathrm{R} \$$} \\
\hline & $\mathrm{N}^{* *}$ & Média & $\begin{array}{l}\text { Desvio } \\
\text { Padrão }\end{array}$ & $\mathrm{N}^{* *}$ & Média & $\begin{array}{l}\text { Desvio } \\
\text { Padrão }\end{array}$ \\
\hline Menos de 1 SM" & 34 & 1,56 & 1,40 & 26 & 10,57 & 4,912 \\
\hline 1 a 3 & 329 & 2,19 & 1,98 & 315 & 11,42 & 5,06 \\
\hline 3 a 4 & 4 & 1,02 & 0,87 & 4 & 10,67 & 4,91 \\
\hline 4 a 6 & 129 & 2,08 & 1,53 & 124 & 13,32 & 6,47 \\
\hline 7 a 9 & 65 & 2,47 & 1,78 & 65 & 12,48 & 4,70 \\
\hline 10 a 15 & 41 & 2,52 & 1,90 & 37 & 13,14 & 4,23 \\
\hline 16 a 20 & 9 & 2,50 & 1,17 & 8 & 14,98 & 4,81 \\
\hline Mais de $20 \mathrm{SM}^{*}$ & 6 & 2,00 & 1,26 & 7 & 20,92 & 7,85 \\
\hline TOTAL & 617 & 2,18 & 1,82 & 586 & 12,17 & 5,47 \\
\hline
\end{tabular}

*Salário mínimo; * Tamanho da amostra.

quilograma de carne. Além disso, Coelho et al. (2009) exemplificam que o aumento da renda tende a elevar o consumo domiciliar de produtos como carne bovina de primeira e diminuir o consumo de produtos básicos, como arroz e feijão. Desse modo, é possível inferir que o poder aquisitivo da população interfere na compra dos diferentes cortes bovinos consumidos.

A partir dos resultados do presente estudo, e considerando a carência de informações científicas nas diferentes regiões econômicas do Rio Grande do Sul, evidencia-se um novo campo de pesquisas na cadeia da carne bovina que busca estabelecer a relação da renda mensal familiar, do comportamento dos preços e dos principais cortes escolhidos, em nível de consumidor. Também, sugere-se investigar os atributos considerados importantes pelos consumidores nas ocasiões em que a carne é consumida, assim como quais os tipos de pratos e o tempo gasto no preparo de pratos em que a carne bovina for utilizada.

\section{CONCLUSÕES}

Os consumidores santamarienses consomem grande quantidade de carne bovina quando comparado ao consumo per capita nacional, e a costela é o principal corte de preferência. O maior percentual de entrevistados auferem de 1 a 3 salá- rios mínimos mensais. Ainda, sugere-se que existe uma tendência a aumentar o consumo e valor pago por quilograma de carne bovina na medida em que aumenta o poder aquisitivo do consumidor. Portanto, é possível inferir que o poder aquisitivo da população interfere na compra dos diferentes cortes bovinos consumidos.

Pode-se observar que independente da renda da população, a escolha pelo local de compra do produto cárneo é atribuída preferencialmente a proximidade da residência dos entrevistados. Além disso, a análise dos atributos da carne bovina que foram considerados importantes pelos consumidores no momento da compra pode favorecer o desenvolvimento e a implementação de estratégias eficazes por parte dos diferentes elos da cadeia produtiva.

$\mathrm{O}$ fato do consumidor estar disposto a pagar por uma carne certificada pela maciez é extremamente relevante, pois demonstra as exigências de qualidade que vem sendo requeridas por esta parte da população.

\section{REFERÊNCIAS BIBLIOGRÁFICAS}

AYMERICH, T.; PICOUET, P. A.; MONFORT, J. $\mathrm{M}$. Decontamination technologies for meat products. Meat Science, v. 78, p. 114-129, 2008. 
BARCELLOS, J. O. J. et al. Consumer perception of Brazilian traced beef. Revista Brasileira de Zootecnia, v. 41, p. 771-774, 2012.

BENÍTEZ, R. J. et al. Determinación de los factores que afectan el mercado de carne bovina en México. Agrociencia, v. 44, n. 1, p. 109-119, 2010.

BLISKA, F. M. M; PARRÉ, J. L.; GUILHOTO, J. J. M. O programa de produção de carne qualificada de bovídeos no Estado de São Paulo sob o enfoque da Teoria dos Jogos. Informações Econômicas, v. 28, n. 2, 1998.

BRISOLA, M. V.; CASTRO, A. M. G. Preferências do consumidor de carne bovina do Distrito Federal pelo ponto de compra e pelo produto adquirido. Caderno de Pesquisas em Administração, v. 12, n. 1, p. 81-99, 2005.

CANFAX RESEARCH SERVICES (CANFAX). The Global Cattle Cycle. 2012. Disponível em: $<$ http://www.canfax.ca/Samples/The\%20Global\%20Cattle\%20Cycle\%20Sept\%202012.pdf>. Acesso em: 16 jan. 2013.

CACCIAMALI, M. C. Distribuição de renda no Brasil: persistência do elevado grau de desigualdade. In: PINHO, D.; VASCONCELLOS, M. A. S. Manual de Economia, São Paulo: Ed. Saraiva, 2002. p. 406-422.

COELHO, A. B.; AGUIAR, D. R. D.; FERNANDES, E. A. Padrão de consumo de alimentos no Brasil. Revista de Economia e Sociologia Rural, v. 47, n. 2, 2009.

DE CARVALHO, T. B.; BACCHI, M. R. P. Estudo da Elasticidade-renda da demanda de carne bovina, suína e de frango no Brasil. In: Anais do XXXV ENCONTRO NACIONAL DE ECONOMIA. 2007. Anais... ANPEC-Associação Nacional dos Centros de Pós-graduação em Economia, 2007. Disponível em:

$<$ http://www.anpec.org.br/encontro2007/artigos/ A07A160.pdf > . Acesso em: 06 ago 2013.

DE VASCONCELLOS, M. M. et al. Avaliação do perfil e preferências dos consumidores de carne no Pampa gaúcho. In: VI SIAPE - ANAIS DO SALÃO INTERNACIONAL DE ENSINO, PESQUISA E EXTENSÃO, v. 4, n. 2, 2012. Anais... Bagé: Salão internacional de ensino, pesquisa e extensão, 2012.
DELGADO, R. T. et al. Caracterización del consumidor de carne bovina en la zona metropolitan del Valle de México. Agrociencia, v. 46, n. 1, p. 75-86, 2012.

\section{FOOD AND AGRICULTURE ORGANIZATION}

(FAO). Food outlook: Biannual report in global food markets. 2013. Disponível em: <http://www. fao.org/docrep/018/a1999e/a1999e.pdf>. Acesso em 21 jul. 2013.

FARIAS, J. L. et al. Comparação entre o perfil dos consumidores de carnes das cidades de Rio Grande e Bagé do estado do Rio Grande do Sul. In: IV SIAPE - ANAIS DO SALÃO INTERNACIONAL DE ENSINO, PESQUISA E EXTENSÃO, v.2, n.1, 2010, Bagé. Anais... Bagé: Salão internacional de ensino, pesquisa e extensão, 2010.

FERREIRA, G. C. Gerenciamento de cadeia de suprimentos: novas formas de organização na cadeia da carne bovina do Rio Grande do Sul. 2002. 217 f. Tese (Doutorado em Administração)-Universidade Federal do Rio Grande do Sul, Porto Alegre, 2002.

GIL, A.C. Métodos e técnicas de pesquisa social. São Paulo: Atlas, 1999. 206 p.

Instituto Brasileiro de Geografia e Estatística (IBGE). Indicadores de 2004 a 2011: Pessoas de 10 anos ou mais de idade, por Grandes Regiões, segundo o sexo e as classes de rendimento mensal - 2011. 2012. Disponível em:

$<$ http://www.ibge.gov.br/home/estatistica/populacao/trabalhoerendimento/pnad2011/default. shtm>.Acesso em: 06 ago 2013.

KOTLER, P. Administração de marketing: análise, planejamento, implementação e controle. 5. ed. São Paulo: Atlas, 1998. 725 p.

MAZZUCHETTI, R. N.; BATALHA, M. O. O comportamento do consumidor em relação ao consumo e às estruturas de comercialização da carne bovina na região de Amerios/Pr. Varia scientia, v. 4, n. 8, p. 25-43, 2004.

MONTEIRO, D. M. S.; CASWELL, J. A. The economics of implementing traceability in beef supply chains: trends in major producing and trading countries. 2004. Disponível em: <http://dx.doi. org/10.2139/ssrn.560067>. Acesso em: 16 jul. 2013. 
NEUMAN, W.L. Social research methods: qualitative and quantitative approaches. 7. ed. Toronto: Pearson, 2009.

PATIÑO, H. O. et al. Desafios e oportunidades das alianzas mercadologicas na cadeia produtiva da carne bovina. Revista Colombiana de Ciencias Pecuarias, v. 21, n. 1, 2008.

PES, D. A.; DE FIGUEIREDO, M. G.; FIGUEIREDO, A. M. R. Análise econométrica da oferta e demanda de carne bovina. Revista de Economia da UEG, v. 8, n. 1, p. 54-73, 2012.

PINHEIRO, M. C.; GOMES, F. E.; LOPES, G. N. Perfil e preferência de consumo da carne bovina na cidade de Boa Vista-Roraima (RR). Revista agroambiente online, v. 2, n. 1, p. 28-36, 2010.

SCHLINDWEIN, M. M.; KASSOUF, A. L. Análise da influência de alguns fatores socioeconômicos e demográficos no consumo domiciliar de carnes no Brasil. Revista de Economia e Sociologia Rural, v. 44, n. 03, p. 549-572, 2006.

SEPÚLVEDA, W. S.; MAZA, M. T.; PRADO, L. Aspects of quality related to the consumption and production of lamb meat. Consumers versus producers. Meat Science, v. 87, p. 366-372, 2011.

SILVA, R. A. M. S. Porque estudar o comportamento do consumidor de carnes? Informativo da Cadeia da Carne Bovina do Pantanal Mato-Grossense, n. 4, p. 01-04, 2009.

SILVEIRA, V. C. P.; VIANA, J. G. A.; WERNER JÚNIOR, C. Preço pago pelo consumidor de carne bovina nas diferentes regiões econômicas do Rio Grande do Sul, Brasil. Ciência Rural, v. 39, n. 4, p. 1212-1218, 2009.

VELHO, J. P. et al. Disposição dos consumidores porto-alegrenses à compra de carne bovina com certificação. Revista Brasileira de Zootecnia, v. 38, n. 2, p. 399-404, 2009.

VIANA, J.G.A., SILVEIRA, V.C.P. A influência das diferentes regiões econômicas do Rio Grande do Sul no preço pago pela carne bovina em nível de varejo. In: SEMINÁRIO DE INICIAÇÃO CIENTÍFICA DA UNISC, 11, 2005, Santa Cruz do Sul, RS. Anais... Santa Cruz do Sul: Pró-reitoria de Pesquisa e Pós-graduação, 2005. (CD-ROOM). 